\title{
A Química dos Cosméticos: Usando a Contextualização e a Interdisciplinaridade como Subsídio para o Ensino de Química
}

\author{
Lioran Fagner Bento de Oliveira* (Graduando em Química na Universidade Federal de Campina \\ Grande (UFCG);
}

J osé Carlos Oliveira Santos (Professor da UABQ/CES na Universidade Federal de Campina Grande UFCG)

*E-mail: lioran.ace@gmail.com

\begin{abstract}
Resumo: A Química é uma das disciplinas do currículo escolar em que os alunos apresentam grandes dificuldades de aprendizagem dos conteúdos. Essas dificuldades podem ser resultantes da falta de métodos que atraiam a atenção e motivem a aprendizagem. E é por isso que o objetivo desse projeto é trazer para os discentes subsídios tanto teóricos quanto práticos que tornem as aulas de química mais atraentes para facilitar o aprendizado do aluno. O projeto foi uma realização do PIBID/Química da UFCG campus Cuité, executado na Escola de Ensino Médio Inovador Professor Lordão, situada na cidade de Picuí-PB, particularmente no ensino médio. Esse trabalho foi desenvolvido em duas etapas sendo uma delas teóricas que circunda a temática que está sendo trabalhada e a outra as aulas foram puramente experimentais. Foi aplicado um questionário na turma de 3 o ano da escola citado acima, para analisar os conhecimentos prévios dos alunos bem como o interesse pela disciplina de química. $O$ uso de novas estratégias para dentro da sala de aula proporciona uma aprendizagem significativa, como a temática dos cosméticos que está presente no cotidiano de todos, ajudando assim na construção do conhecimento do discente.
\end{abstract}

Palavras-chave: Metodologias de ensino; aulas práticas; ensino médio; cosméticos; contextualização

Espaço reservado para organização do congresso. 


\section{I ntrodução}

O ensino de química, durante muito tempo, limitou-se apenas em usar de metodologias tradicionais que não possuem nenhuma atração para os alunos do ensino médio. Segundo Lima et al. (2000), na maioria das vezes, tem-se resumido a cálculos matemáticos e memorização de fórmulas e nomenclaturas de compostos, o que não valoriza os aspectos conceituais dos conteúdos de química. Isso implica de forma direta numa maior desmotivação e conseqüentemente num baixo rendimento dos alunos em sala de aula.

Assim, a Química é uma das disciplinas do currículo escolar em que os alunos apresentam grandes dificuldades de aprendizagem dos conteúdos. Essas dificuldades podem ser resultantes da falta de métodos que atraiam a atenção e motivem a aprendizagem. Nos últimos anos, muito tem se discutido sobre a necessidade de reformulação das metodologias ensino. Segundo Cunha (2012), o desenvolvimento dos discentes é considerado conseqüência do trabalho do professor. A ideia do ensino despertado pelo interesse do estudante passou a ser um desafio à competência do docente. $\mathrm{O}$ professor não pode exercer apenas o papel de transmissor de conhecimentos prontos e acabados e sem qualquer relação com as vivências dos discentes, ele deve agir como mediador do conhecimento, uma vez que se sabe que conhecimento não se transmite, conhecimento se ajuda a construir.

Ainda segundo Cunha (2012), o interesse dos alunos se tornou a força motora do processo de aprendizagem, e o docente, o formador de situações que incentivem a aprendizagem. E é a partir daí que surge a necessidade da criação de metodologias de ensino que possam ser utilizadas como ferramentas motivadoras para a aprendizagem dos conteúdos de química, para assim poder despertar o interesse do estudante. Segundo Moraes (2003, apud MÜNCHEN, 2012) “é preciso partir do conhecimento dos alunos, percebido por suas manifestações e discursos, constituído no meio social em que se inserem”.

Segundo Nogueira (2015), os cosméticos fazem parte do cotidiano das pessoas desde a antiguidade, que já utilizavam, por exemplo, alguns materiais como leite e mel para banhos com o intuito de amaciar a pele. Mesmo sem saber nada relacionado às suas propriedades e a razão de acontecer àqueles determinados efeitos, as pessoas faziam uso dos mais diferentes tipos de produtos, repassando um conhecimento popular historicamente acumulado com o objetivo do embelezamento, bem-estar e higiene. Nessa perspectiva, os cosméticos são um possível exemplo de produtos que estão relacionados a diversos conceitos científicos da disciplina de química e que estão presentes na vida de boa parte da população (MUNCHEN, 2012).

Levando em conta essas considerações e tendo como base uma proposta de contextualização de forma interdisciplinar, o subprojeto PIBID/Química da UFCG campus Cuité, que tem a realização de suas práticas na Escola de Ensino Médio Inovador Professor Lordão, situada na cidade de Picuí-PB se propôs a desenvolver um projeto que tem como intuito ser um subsidio teórico e prático para as aulas de química, com o papel de tornar a disciplina de química mais atraente para os discentes, fazendo uso de uma assunto mais próximo e comum na sociedade atual fazendo a interligação do mesmo com o conhecimento científico do currículo escolar. O projeto visa ainda proporcionar aos discentes uma nova proposta de ensino que se diferencie das propostas convencionais, tornando mais dinâmico o ensino de química, para com isso possibilitar uma maior interação entre os alunos e o professor, bem como promover uma aprendizagem significativa. O trabalho também visou analisar a contribuição desse método para o desenvolvimento dos conhecimentos dos discentes.

\section{Metodologia}

O presente trabalho foi desenvolvido em duas etapas. A primeira etapa teve como foco toda a teoria que circunda a temática que estava sendo trabalhada, não se restringindo exclusivamente a uma disciplina isolada, mas sim permitindo a interdisciplinaridade entre várias pontes de conhecimento. Essa etapa foi dividida em cinco aulas, onde em todas foram usados matérias auxiliares como projetor de imagens (data show), lousa e questionários.

A primeira aula se restringiu em mostrar como seria desenvolvido o projeto para motivar e tentar analisar o interesse dos alunos em participar da aplicação do mesmo, para isso foi feito uso de conversas informais. A segunda aula teve como objetivo tornar do conhecimento de todos os discentes o tema a ser trabalhado, e saber o nível de familiaridade que os alunos tinham com o mesmo. Ainda nessa aula foi aplicado um questionário com intuito de resgatar os conhecimentos prévios e analisar o 
interesse e dos alunos na disciplina de química, bem como nas metodologias de ensino desenvolvida até então. A terceira aula teve como título "A história dos cosméticos" e teve como finalidade contextualizar o tema através de fatos históricos, evidenciando o uso dos cosméticos desde a antiguidade, bem como os aspectos biológicos e químicos, permitindo que os alunos quebrassem paradigmas que o conhecimento não está interligado. Na quarta aula, foram trabalhados os conceitos químicos de funções orgânicas, ligações e polaridade, que estão ligados direta ou indiretamente com a temática. Apesar da aula ser exclusivamente para retratar características químicas, permitiu associar aplicações físicas e biológicas. Na quinta aula, a última da primeira etapa, foram levadas para a sala embalagens de cosméticos a fim de ensinar a proceder à leitura dos seus rótulos. Ainda nessa aula foi feito um alerta para os perigos em relação ao mau uso e ao uso em excesso dos cosméticos.

Na segunda etapa, as aulas foram puramente experimentais, realizadas no pátio, devido à escola não possuir em suas dependências um laboratório ou sala que contivesse uma bancada que comportasse todos os alunos ao seu redor, sem apresentar riscos aos mesmos. Antes de começar a primeira aula experimental foi alertado aos discentes sobre o comportamento que se deveria ter ao manusear os materiais e as substâncias que seriam utilizadas. Foram usados materiais estritamente alternativos devido à falta de equipamentos de laboratório na escola.

A aula prática consistiu na elaboração de um extrato vegetal baseado na solubilização. Essa aula teve como objetivo produzir um extrato de plantas conhecidas e de fácil acesso. Foram utilizadas para esse experimento a hortelã e a casca de laranja. Primeiramente se triturou o material, para depois macerar. Durante a maceração colocou-se uma solução com álcool para favorecer a captura das propriedades da planta. Os cortes ajudaram a permitir que o álcool interagisse mais rápido. Deixou- se descansando e depois colocou-se o óleo mineral, que por sua vez se misturou com o óleo essencial da planta. Por fim, esquentou-se a mistura com o intuito de que o álcool presente pudesse evaporar. Quanto mais álcool evaporar mais puro é o extrato e também maior a quantidade de óleo essencial.

\section{Resultados e Discussões}

Com base na proposta de correlacionar o tema cosméticos com os conceitos que o envolve, tendo como referência a interdisciplinaridade e a contextualização, aplicou-se aos alunos do $3^{\circ}$ ano da Escola de Ensino Médio Inovador Professor Lordão, situada na cidade de Picuí-PB um questionário inicial, que visava analisar quais os conhecimentos prévios dos alunos, bem como o interesse dos mesmos na disciplina de química e nas metodologias de ensino desenvolvidas até então. O questionário era composto por sete perguntas simples, onde as três questões consideradas mais importantes estão expostas a seguir:

Quadro 1 - Três das questões presentes no questionário inicial.

\begin{tabular}{|c|}
\hline \\
\hline 2- Qual a sua opinião em relação às metodologias usadas pelos seus professores? \\
\hline $\begin{array}{l}\text { 3- Você conhece alguma substância presente em algum tipo de cosmético? Cite } \\
\text { algumas dessas substâncias. }\end{array}$ \\
\hline
\end{tabular}

Fonte: Dados da pesquisa

Depois da aplicação do questionário, analisando a primeira e a segunda questões que foram as perguntas com um maior número de respostas, e com base nas conversas tidas com alunos durante o primeiro momento em sala de aula, foi visto que mais da metade da turma não gostava da disciplina de química. E que na maioria dos casos os alunos que responderam não gostar da disciplina, disseram também considerar a metodologia de ensino dos seus professores razoável ou ruim, colocando como explicação a monotonia das aulas, a falta de experimentos e principalmente por não conseguirem relacionar os conceitos com o seu cotidiano.

A terceira questão por sua vez, faz relação com o conhecimento químico de cada aluno. Alguns alunos conseguiram responder sem muita dificuldade, colocando vários exemplos de substâncias, porém outra parte dos alunos que responderam que conheciam não citou exemplos. E por fim, a minoria dos alunos que respondeu o questionário deixou a questão sem resposta. 
Quando foi lançada e mostrada a proposta de trabalhar cosméticos em sala de aula, por ser um tema atual e presente na vida de todos, foi perceptível uma grande aceitação por parte dos discentes, que ficaram bastante motivados e participativos desde o momento da proposta até o encerramento do projeto. E então a partir desse aceite, deu-se inicio a aplicação do projeto. As aulas teóricas tiveram um enfoque interdisciplinar trabalhando aspectos históricos, biológicos e químicos, e estavam sempre abertas a questionamentos e a relatos de experiências vivenciadas por parte dos alunos. Em seguida, foi proposto um momento de atividade prática que consiste na produção de extratos vegetais. A turma foi dividida em grupos para facilitar participação e socialização de todos. Todos os alunos puderam realizar vários procedimentos, desde medir os volumes de álcool e óleo mineral que iriam ser usados, até levar ao fogo para esquentar a mistura a fim de que o álcool evaporasse. Veja na Figura 1 imagens da aula.

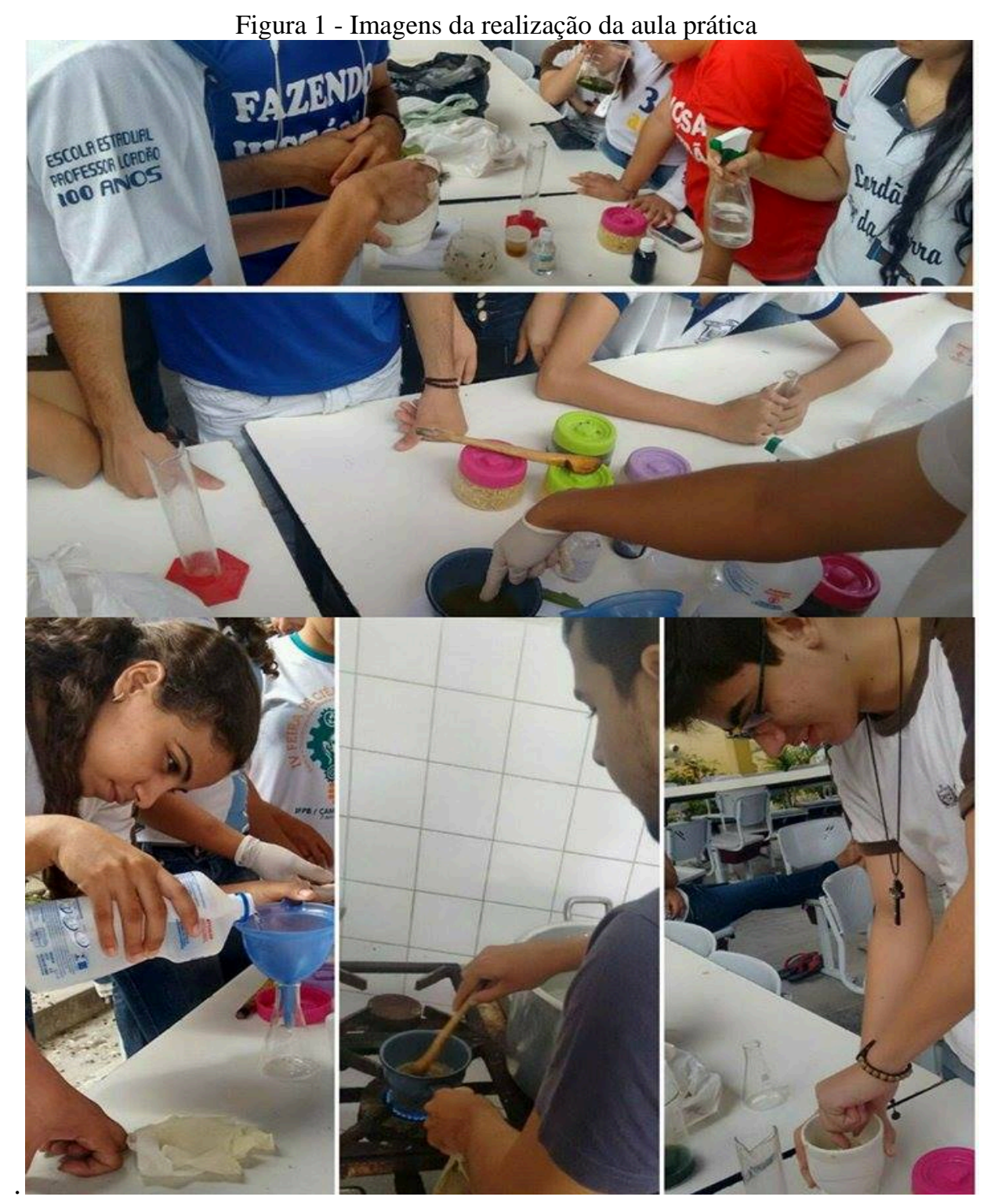

Fonte: Dados da pesquisa

Com essa aula prática foi possível proporcionar a interação, motivação e a participação de todos os envolvidos. Por consequência dessa atividade pôde-se ajudar na construção de um conhecimento científico, bem como promover uma evolução nos conhecimentos já existentes e na forma de pensar de cada aluno individualmente. Isso pôde ser percebido através de novas perguntas feitas após o termino da prática, pois os alunos conseguiram responder com maior propriedade aos 
questionamentos realizados. A partir desse método eles puderam perceber a relação existente entre o conhecimento e o cotidiano.

\section{Considerações Finais}

O uso de novas estratégias que consigam proporcionar uma aprendizagem significativa, correlacionando uma temática como cosméticos, que está presente no cotidiano de todos, com o conhecimento científico que o envolve, obteve resultados positivos como um aumento na motivação e participação, pois mesmo que os alunos tenham afirmado não gostarem de química, esses métodos conseguem motivar aprendizagem através da interação entre professor-aluno e aluno-aluno.

É perceptível também que os discentes normalmente se mostram entusiasmados quando o objeto de estudo é algo presente em seu cotidiano. A familiaridade dos alunos com a temática proporcionou melhores debates, que na maioria das vezes estavam acompanhados de relatos de suas próprias vivências ou de conhecidos, sobre o uso de cosméticos. A utilização de novas metodologias no ensino de química é cada vez mais necessária, pois se sabe que o professor deve agir como mediar do conhecimento, buscando sempre meios para que os seus alunos possam compreender com a maior clareza possível cada assunto ministrado.

Através da metodologia usada durante a aplicação desse trabalho conseguiu-se alcançar todos os objetivos pretendidos. A interação, a motivação e a construção de competências e habilidades foram atingidas pelos alunos envolvidos na proposta didática. Após a intervenção os alunos apresentaram domínio dos conteúdos, expressando conhecimento detalhado, sendo capaz de fazer relação com toda a matéria vista em sala de aula, reconhecendo assim, a importância da disciplina de química.

\section{Chemistry of Cosmetics: Using Context and Interdisciplinarity as allowance for Chemistry Teaching}

Albstract: Chemistry is one of the disciplines of the school curriculum in which students have great difficulty in learning the content. These difficulties can be caused by a lack of methods to attract attention and motivate learning. And that's why the goal of this project is to bring the students both theoretical and practical subsidies that make the most attractive chemistry classes to facilitate student learning. The project was a realization of PIBID / Chemistry UFCG campus Cuité, performed in High School Innovative Teacher Lordão, located in the city of Picuí-PB, particularly in high school. This work was developed in two stages one of which theoretical surrounding the issue being worked and the other classes were purely experimental. A questionnaire in class 3rd year of school cited above was applied to analyze the students' prior knowledge and interest in the discipline of chemistry. The use of new strategies into the classroom provides a meaningful learning, such as cosmetics theme that is present in the daily lives of everyone, thus helping in the construction of the student's knowledge.

Keywords: Teaching methodologies; practical classes; high school; cosmetics; contextualization

\section{Referências bibliográficas}

LIMA, J. A contextualização no Ensino de Cinética Química. Química Nova da Escola. n. 11, 2002.

CUNHA, M. B. J ogos no ensino de química: considerações teóricas para sua utilização em sala de aula.

Química Nova na Escola. v.34, p. 92-98, 2012.

MUNCHEN, S. Cosméticos: uma possibilidade para abordar funções orgânicas no ensino médio, in:

NUTES, Universidade Federal doRio de Janeiro, 2012. 
NOGUEIRA, E. P. A problemática do Ensino de Química Orgânica e os Cosméticos, in: SI NEQUI, 2015 